7.

FiLOSOFÍA DEL DERECHO 



\title{
Un REEXAMEN DE LAS TESIS DE STAMMLER Y DE LAS INFLUENCIAS RECIBIDAS POR ELLAS
}

[Re-examination of Stammler's Theses and the Influences behind them]

\author{
María Isabel GARRIDO GÓMEz* \\ Universidad de Alcalá, Alcalá de Henares, España
}

\begin{abstract}
RESUMEN
El trabajo estudia las tesis defendidas por Rudolf von Stammler, quien, como perteneciente a la escuela de Marburgo, vio en la teoría gnoseológica la esencia de la filosofía kantiana. La construcción del pensamiento de Stammler intenta lograr una formulación necesaria y universalmente válida de los conceptos y problemas básicos del derecho desde una perspectiva crítica. Formulación que evidencia posiciones recreadoras de la teoría kantiana, si bien en algunos aspectos se traslucen vínculos con otros autores y escuelas, como Aristóteles, Tomás de Aquino, Suárez, la escuela de derecho
\end{abstract}

\begin{abstract}
This work analyses the theses upheld by Rudolf von Stammler, who, as a follower of the Marburg School, found in the gnoseologic theory, the essence of Kant's philosophy. By building Stammler's thought we seek to reach a necessary and universally valid formulation of the basic concepts and problems of the law from a critical approach. This formulation evidences positions recreating the Kantian theory, and also reveals links to some other authors and schools, such as Aristotle, Thomas Aquinas, Suárez, $\mathrm{La}$ Escuela de Derecho Libre, jurisprudence on interests or the American legal real-
\end{abstract}

RECIBIDO el 30 de diciembre de 2014 y ACEPTADO el 7 de diciembre de 2015

* Profesora Titular de filosofía del derecho. Facultad de derecho de la Universidad de Alcalá. Dirección postal: Calle Libreros, 27, 28801 Alcalá de Henares (Madrid)-España. E-mail: misabel.garrido@uah.es 
libre, la jurisprudencia de intereses o el realismo jurídico norteamericano. El trabajo intenta desglosar las conexiones y aspectos más significativos, al igual que destacar los elementos separadores que sirven para perfilar bien las teorías propias del autor.

\section{Palabras Clave}

Stammler, Rudolf von - Formalismo jurídico - Teorías kantianas del derecho - Influencia de Kant en Stammler - Derecho justo - Derecho natural. ism. This work breaks down the links and most important aspects, as well as ruling out the separating factors, to properly shape the theories inherent to the author

\section{KEYWORDS}

Stammler, Rudolf von - Legal Formalism - Kant's Theories of Law - Kant's Influence on Stammler - Fair Rule of Law - Natural Law.

\section{LAS TESIS KANTIANAS COMO RAÍCES DEL PENSAMIENTO de STAMmLer y la Relación entre éste y Kant}

Cuando nos referimos al formalismo jurídico, lo hacemos a una corriente muy diversa en sus términos; así, dentro de él se advierte una primera acepción apegada a una teoría de la justicia, en concreto, como dice Bobbio, la de que "el acto justo es aquel que es conforme a la ley, e injusto aquel que está en desacuerdo con ella”. Dicha concepción es formal porque define la acción justa como cumplimiento del deber, de modo que la noción de forma se toma de una de las acepciones más clásicas, la cual mide por un modelo ideal actos o acontecimientos.

En segundo lugar, tras el formalismo jurídico existe una segunda acepción, referida a una teoría particular del derecho. Desde esta perspectiva, el ejemplo de Kant es paradigmático en el sentido de que fija tres notas en el concepto del derecho partiendo del tipo de relación intersubjetiva que abarca o instituye, dado que la relación jurídica se caracteriza según el autor por el hecho de ser externa, recíproca y formal. Por tanto, podemos subrayar que Kant es formalista a la hora de definir el derecho, pero no en la definición de la justicia. Sin embargo, la teoría normativa del derecho, o normativismo, da la posibilidad, a su vez, de considerar un tercer grupo de significados, esto es, una forma de concebir la experiencia jurídica como experiencia sub specie legis y como modo de hacer ciencia del derecho. $\mathrm{Y}$, finalmente, una acepción muy conocida del formalismo jurídico es la que nos remite a la interpretación jurídica. Las cuatro alternativas encierran 
problemas específicos: uno se refiere a la justicia, otro al derecho, otro a la ciencia jurídica y el último a la interpretación jurídica ${ }^{1}$.

Para comenzar el análisis del presente apartado, creo conveniente resaltar algunos aspectos del pensamiento kantiano para, con posterioridad, considerar los que inciden en la teoría de Stammler².

Pues bien, como es conocido, Kant finalizó la Escuela clásica del derecho natural y comenzó la Escuela racionalista o formalista del derecho. El imperativo kantiano se articula, por consiguiente, como un principio formal que no dice lo que se debe hacer, sino cómo y con qué intención se debe obrar, dando un nuevo giro a las relaciones entre la subjetividad y la objetividad.

El apriorismo de la estructura conceptual integrable de la experiencia se emplea a modo de producto de la constitución cognoscitiva humana y de sus facultades mentales. Al hilo de esta estimación, el modelo, al que se adjunta el pensamiento que reduce el tiempo y el espacio a formas de la sensibilidad, arrastra a Kant al idealismo trascendental, posibilitando conocer todo aquello que, por no ser sensible, es racionalmente cognoscible. Puntualmente, a la fe se asigna lo que la razón no ofrece y respecto a lo cual llego, en el límite máximo, a una posición de no saber, supuestos de la existencia de Dios, la moralidad del alma o la libertad del hombre. La gnoseología se erige en instancia formal, donde la primacía de la forma no sólo decide sobre la pendencia metódica estricta -conocimiento a priori y a posteriori como posibilidades de la inducción y de la deducción a través

${ }^{1}$ Boвbio, Norberto, El problema del positivismo jurídico (traducción al castellano de E. Garzón Valdés, México D. F., Fontamara, 2004), pp. 13 ss.; Llano, Fernando, El formalismo jurídico y la teoría experiencial del derecho (Valencia, Tirant lo Blanch, 2009), pp. 33 ss.

${ }^{2}$ Las obras principales de Stammler traducidas al castellano son: STAMMLER, Rudolf von, La génesis del derecho (traducción al castellano de W. Roces, Madrid, Espasa-Calpe, 1925); Economía y derecho según la concepción materialista de la historia. Una investigación filosófico-social (traducción al castellano de W. Roces, Madrid, Reus, 1929); Tratado de filosofía del derecho (traducción al castellano de W. Roces, Madrid, Reus, 1930); Doctrinas modernas sobre el derecho y el Estado (traducción al castellano de J. J. Bremen, México D. F., Compañía General Edit., 1941); La esencia del derecho y de la ciencia del derecho (traducción al castellano y bibliografía de E. Garzón Valdés, Córdoba, Arg., Universidad Nacional de Córdoba, 1958); Sobre el método de la Escuela histórica, [traducción al castellano de R. Atard, en AA. VV., Documentos para el estudio de la Escuela histórica (Madrid, V. Suárez, Madrid, 1960)]; El juez (rad. de E. F. Camus, México D. F., Edit. Nacional, 1981). Las sucesivas citas a obras de Stammler, normalmente se refieren a las de esta lista y sus datos editoriales. 
de los juicios analíticos y sintéticos-, sino que el método científico acaba determinando el objeto gnoseológico ${ }^{3}$.

El derecho positivo es contemplado por Kant como elemento empírico que hay que ordenar en las formas a priori de la razón, adecuado al procedimiento de la ciencia teorizado en la Crítica de la razón pura. De ahí se pasa a una concepción formalista del derecho en sí, con arreglo a un principio a priori de la coordinación de las libertades de los individuos que no tiene en cuenta más que la forma en que deben ser ejercitadas ${ }^{4}$. El concepto del derecho no es obtenible de la experiencia, habla el filósofo de "conjunto de condiciones bajo las cuales es armonizable el arbitrio de uno con el arbitrio del otro según una ley general de la libertad”. Dicha noción se desgrana en que aquél tiene por objeto la relación externa y práctica de una persona con otra, en tanto que sus acciones pueden influirse mediata o inmediatamente; $y$ en que tiene en cuenta la reciprocidad y el hecho de si la relación de cada uno se concilia con la del otro de acuerdo con una ley general, consolidando la seguridad jurídica5 .

En Kant, igual que en toda la moral, el problema del derecho es su pensabilidad general, siendo la libertad la realidad primaria de ambos. La buena voluntad no sopesa los resultados a los que se quiere llegar, tiene en cuenta la acomodación a la ley y, sólo categorizantemente, es pensable una acción como moral. Mas se cree que cualquier acción humana debe ser pensada como libre también en el orden externo, el derecho en sí es libertad y arraiga en el hecho de que el hombre es persona. La ley de la libertad es un imperativo categórico incondicional formulado del modo

${ }^{3}$ Bulygin, Eugenio, Sobre la regla de reconocimiento, en Alchourrón, Carlos E. - Bulygin, Eugenio, Análisis lógico y derecho (Madrid, Centro de Estudios Constitucionales, 1991), p. 381. El método de la reflexión trascendental descubre las leyes inmanentes de la experiencia (sobre lo cual, véase BANFI, Antonio, Il problema epistemologico nella filosofia del diritto e le teorie neo-kantiane, en Rivista Internazionale di Filosofia del Diritto, 2 (1926), pp. 194 ss.; SolarI, Gioele, L'indirizzo neo-kantiano nella filosofia del diritto, en Rivista di Filosofia, 23 (1932), pp. 323-324.

${ }^{4}$ KanT, Immanuel, La metafisica de las costumbres (traducción al castellano y notas de A. Cortina Orts y J. Conill Sancho, Estudio preliminar de A. Cortina Orts, Madrid, Tecnos, 1994), 1ª parte: "Introducción a la doctrina del derecho", \& B, C, D y E, pp. 38 ss. Cfr. también GonZÁLEZ VicÉn, Felipe, Sobre los orígenes y supuestos del formalismo en el pensamiento jurídico contemporáneo, en Anuario de Filosofía del Derecho, 8 (primera época) (1961), pp. 47 ss.

${ }^{5}$ Kant, Immanuel, La metafisica de las costumbres, cit. (n. 4), 1a parte, "Introducción a la doctrina del derecho", \& C, D y E, pp. 39 ss.; El MISMO, Ideas para una historia universal en clave cosmopolita y otros escritos sobre filosofia de la historia (traducción al castellano de C. Roldán y R. Rodríguez Aramayo, "Estudio preliminar" de R. Rodríguez Aramayo, Madrid, Tecnos, 2006), véanse, sobre todo, las proposiciones 4-7. 
que sigue: "Obra de tal modo que la máxima de tu voluntad pueda valer siempre de principio de una legislación universal", distinguiéndose del hipotético, el cual obliga universalmente bajo alguna condición y ordena las acciones según medios que miran a un fin $^{6}$. En definitiva, la pieza clave de la epistemología se funda en la idea de que "es el objeto de los sentidos el que se gobierna por la naturaleza de nuestra facultad de intuición", y que "la experiencia (así constituida) obedece a los conceptos o reglas a priori del entendimiento", sobresaliendo que el sujeto del conocimiento es una pieza nuclear de la teoría y de la construcción "metafísica crítica".

Pues bien, a lo largo de la obra de Stammler, se manifiesta, en consonancia con el neokantismo, cómo se facilita la edificación lógico-formal del derecho ateniéndose a la crítica de la razón kantiana. En él se fusionan la lógica de la Jurisprudencia y las deducciones del derecho natural racionalista, por lo que hay muchas concomitancias entre las doctrinas de ambos. Aquél enlaza con la teoría del conocimiento de Kant y con el uso que los neokantianos hacen de ella, legitimando la Cultura por el reconocimiento del valor de la ciencia. Pero el alejamiento se plasma en que Kant circunscribe la ética a las formas de la lógica (naturalista) y la esencializa sobre el ámbito de las percepciones, configurando Stammler la ciencia de los fines desde el querer. Para la teoría stammleriana, la filosofía del derecho es teoría de sus formas puras, y ambas buscan las condiciones del conocimiento científico, lo a priori del juicio jurídico. Los citados autores aglutinan todo en una imagen formal e incondicionada de lo pensable. El mecanismo que Kant asoció a la zona situada en la emanación de toda experiencia, Stammler lo aplica a una zona dentro de la experiencia y somete a elaboración metafísica un tema científico de sociología. De este modo, el espíritu animador es el demostrado en las nociones del racionalismo y del orden ${ }^{8}$.

${ }^{6}$ KANT, Immanuel, La metafisica de las costumbres, cit. (n. 4), 1 a parte, "Introducción a la metafísica de las costumbres”, IV, pp. 26 ss., y 2a parte, "Introducción a la doctrina de la virtud", III, pp. 235 y 236. Véase también EL MISMO, Fundamentación para una metafísica de las costumbres (traducción al castellano y "Estudio preliminar" de R. Rodríguez Aramayo, Madrid, Alianza, 2002), A 51, pp. 103 y 104. Además, FAssò, Guido, Historia de la filosofía del derecho (traducción al castellano de J. F. Lorca Navarrete, Madrid, Pirámide, 1982), II, pp. 266 ss.; Truyol, Antonio, Historia de la filosofía del derecho y del Estado (Del Renacimiento a Kant) (Madrid, Alianza, 2007), II, pp. 393 ss.

${ }^{7}$ ColOmer, José Luis, La teoría de la justicia de Immanuel Kant (Madrid, Centro de Estudios Constitucionales, 1995), pp. 21 y 22; PASCHER, Manfred, Einführung in den Neukantianismus (München, Fink, 1997).

${ }^{8}$ Gomez De La Serna, José, Filósofos modernos del derecho. Los neokantianos, en Anuario de Filosofía del Derecho, 1 (primera época) (1953), p. 130; LEGAz, Luis, 
Kant analiza los principios racionales a priori de la conducta de los hombres, y fija que la conducta será jurídica o moral en función del motivo que la determina' ${ }^{9}$ Y, parejamente, lo que preocupaba a Stammler era delimitar el fenómeno del derecho en el plano volitivo, porque su finalidad es la de relacionar unos medios y unos fines ${ }^{10}$, pudiéndose reparar, como hace acertadamente Lord D. Lloyd, que la concepción del derecho natural se despliega desde la concepción kantiana de la ley moral ${ }^{11}$.

El concepto del derecho de Kant se investiga en la razón práctica y es la raíz de una posible legislación positiva. El derecho es intersubjetivo, para que la relación jurídica exista, son inexcusables dos voluntades conscientes de su capacidad con el fin de lograr su objeto; y es un orden coactivo, prescribe el modo en que una acción debe ser realizada ${ }^{12}$. El concepto ofrecido se corresponde con el ideal de la libertad. La lógica consiste en

Filosofía del derecho (Barcelona, Bosch, 1979), pp. 34 y 35. Y, en general, véase HöFFE, Otfried, Immanuel Kant (traducción al castellano de Diorki, Barcelona, Herder, 1986); Lacroix, Jean, Kant et le kantismo (Paris, Presses Universitaires de France, 1998).

${ }^{9}$ Kant, Immanuel, La metafísica de las costumbres, cit. (n. 4), 2a parte, "Prólogo" a los Principios metafísicos de la doctrina de la virtud, pp. 223 ss.; EL MISMO, Fundamentación para una metafisica de las costumbres, cit. (n. 6), A 97 ss., pp. 140 ss.

${ }^{10}$ Atienza, Manuel, El sentido del derecho (Barcelona, 2003), pp. 191 y 192. Dice Rodríguez Paniagua, Historia del pensamiento jurídico (Siglos XIX y XX) (Madrid, Facultad de Derecho de la Universidad Complutense de Madrid, 1997), II, p. 487, que su conexión con la filosofía kantiana hay que buscarla en el sentido de la legalidad, de la generalidad de la ley y de la filosofía moral de Kant. Como la fórmula del imperativo categórico expresa la necesidad de obrar con arreglo a un motivo que pueda convertirse en ley universal, y es esta universalidad la que determina la moralidad, el puro querer de Stammler sería una pura abstracción de todo contenido concreto de voluntad. Igualmente, Recaséns, L., Filosofía del derecho (México D. F., Porrúa, 1997), p. 456 había percibido ya, en la comunidad de hombres librevolentes, el recuerdo de la idea de voluntad pura de la moral kantiana que obedece a una forma lógica de universalidad, a la vez que late la voluntad general de Rousseau.

${ }^{11}$ LLOYD, Lord Denis, La idea del derecho ¿perversidad represora o necesidad social? (traducción al castellano de R. Aguilar de Ben y M. Barat, Madrid, Civitas, 1985), pp. 96 y 97.

${ }^{12}$ Fasso, Guido, Historia, cit. (n. 6), II, pp. 269-271. En concreto, véase KanT, Immanuel, La metafisica de las costumbres, cit. (n. 4), especialmente "Introducción a la doctrina del derecho", \& C, pp. 39-41. El derecho cosmopolita propuesto coordina las libertades de los individuos y de los Estados representando el deber superior del hombre [KanT, Immanuel, Sobre la paz perpetua (traducción al castellano de J. Abellán, presentación de A. Truyol Sierra (Madrid, Alianza, 2002)]. Cfr. también Aftalión, Enrique R. - Vilanova, José, con la colaboración J. Raffo, Introducción al derecho (Buenos Aires, Abeledo-Perrot, 1994), p. 250; Clavel, Maurice, Critique de Kant (París, Flammarion, 1980). 
las reglas formales de toda clase de pensar, componiendo una ciencia del razonamiento, "la ciencia de las leyes necesarias del entendimiento y de la razón en general", y parte del principio de que "todo en la naturaleza, en el mundo animado y en el inanimado, ocurre según reglas, aun cuando no las conozcamos nunca", reglas que son pensables por sí y omiten todas las diferencias que guarda el concepto. Dentro de estos paradigmas, el método trascendental resalta los fundamentos lógicos del conocimiento como una actividad que construye el entendimiento ${ }^{13}$.

Siguiendo estas directrices, Stammler llamó la atención sobre la urgencia de fabricar una teoría del conocimiento jurídico. Fortaleció la separación entre las ciencias de la naturaleza y las de los fines, a lo que contribuyó la independencia metódica de la jurídica, y superó el positivismo al dotar a la ciencia de la pauta del derecho recto ${ }^{14}$. El punto de partida estriba en que el derecho es una forma de ordenar la convivencia, comprendiendo que es un proceso formal armonizador de los fines individuales y sociales, ajustados los primeros a los objetivos comunitarios de un ideal social de justicia cristalizado en una "comunidad de hombres de voluntad libre". El concepto -insiste- es un a priori por el que imputamos la naturaleza de juridicidad a los sistemas de derecho positivo, y la idea es la respuesta acerca de la correspondencia con la justicia de un contenido de derecho ${ }^{15}$.

${ }^{13}$ Quintana, Fernando, El tema del concepto y de la idea en Kant y en Stammler, en Revista de Ciencias Sociales, 20 (1982), pp. 181 ss.; WARAT, Luis, Los presupuestos kantianos y neokantianos de la teoría pura del derecho, en Revista de Ciencias Sociales, 20 (1982), p. 389. Véase, además, KANT, Immanuel, Crítica de la razón pura (traducción al castellano de M. García Morente, ed. abreviada, introducción, notas y anexos de J. J. García Norrro y R. Rovira (Madrid, Tecnos, 2004), 2a parte, Introducción: La idea de una lógica trascendental, pp. 149 ss.; Fassò, Guido, Historia, cit. (n. 6), vol. 2, pp. 271 y 272.

${ }^{14}$ Cfr., entre otras, las críticas de CATHRein, Victor, Filosofía del derecho. El derecho natural y el positivo (traducción al castellano de A. Jardón y C. Barja, Madrid, Reus, 2002), pp. 145 ss. Y Binder, Julius, Rechtsbegriff und Rechtsidee, Bemerkungen zur Rechtsphilosophie Rudolf Stammlers (Aalen, Scientia, 1967); Kaufmann, Erich, Kritik der neukantischen Rechtsphilosophie (Aalen, Scientia, 1964) [hay traducción al castellano italiana: Critica della filosofia neokantiana del diritto (Napoli, Edizioni Scientifiche Italiane, 1992)]; KÜRY, E. E., Kritische Bemerkungen zu Stammlers Lehre, en Revue Internationale de Théorie du Droit et de Sociologie Juridique, 6 (1931-1932), pp. 158 ss.; Larenz, Karl, Metodología de la ciencia del derecho (traducción al castellano de M. Rodríguez Molinero, Barcelona, Ariel, 2001), pp. 112 y 113; RECASÉnS, Luis, Filosofía del derecho, cit. (n. 10), pp. 449 ss.; SÁnchez de Bustamante, Antonio, Stammler (ensayo de valoración) (La Habana, 1931); Wu, John C.H., Stammler and his Critics, en Modern Legal Philosophy Series (Nueva York, 1969), VIII, Ap. 2.

${ }^{15}$ Ginsberg, Morris, La Philosophie du Droit de Rudolf Stammler, en Archives de Philosophie du Droit (1932), pp. 564 ss.; NúÑEz EnCABO, Manuel, El derecho, 
De tal manera, es sostenible que Stammler fue el renovador de las tradicionales meditaciones axiológicas a la luz de la doctrina kantiana sobre la distinción entre concepto e idea, siendo relevante que, gracias al concepto del derecho, se separan las normas jurídicas de los fenómenos naturales, de la moral, de los usos sociales y del poder arbitrario ${ }^{16}$.

\section{Claves del Pensamiento jurídico de Stammler CONFORME CON SU VINCULACIÓN CON KANT Y OTROS AUTORES Y ESCUELAS}

Según el hilo conductor de los argumentos esgrimidos, dentro de la teoría de Stammler los aspectos en los que mejor se percibe la influencia de otros autores y escuelas, esencialmente de Kant, son los del concepto del derecho, su idea y el ideal social, el derecho justo y el natural, y la reflexión sobre el derecho y la moral.

\section{El concepto del derecho, su idea y el ideal social.}

La pretensión de estudiar una materia y mostrar su sustantividad conduce a configurarla conceptualmente. Por esta razón, Stammler responde al interrogante de qué es el derecho, el cual radica en el modo de concebirlo. Por modo entiende una comprensión que conteste a tres cuestiones: qué es, por qué es y para qué es, delimitadoras de sus cualidades, estructura y ámbito de la realidad ${ }^{17}$. El derecho -se sostiene- no es absorbible de la experiencia, entraña una categoría de la dimensión de la voluntad, habiendo una relación de la parte con el todo. El hecho de denominar jurídica una institución supone un concepto, porque la existencia jurídica es a causa del concepto del derecho que la determina ${ }^{18}$.

ciencia y realidad social (Madrid, Universitas, 1993), p. 138; Palombella, Gianluigi, Filosofía del derecho moderna y contemporánea (traducción al castellano de J. Calvo González, Madrid, Tecnos, 1999), pp. 178-179.

${ }^{16}$ Pérez Luño, Antonio Enrique, con la colaboración de C. Alarcón Cabrera R. González-Tablas - A. Ruiz de la Cuesta, Teoría del derecho. Una concepción de la experiencia jurídica (Madrid, Tecnos, 2008), p. 76; Quintana, Fernando, El tema, cit. (n. 13), pp. 177, 195- 196.

${ }^{17}$ Véase FrançoIs, Lucien, Le problème de la défnition du droit: Introduction à un cours d'évolution de la philosophie du droit à l'époque contemporaine (Lieja, Facultad de Derecho, Economía y Ciencias Sociales de la Universidad de Lieja, 1978); Williams, Glanville L., The Controversy Concerning the Word Law, en Archiv für Recht-und Sozialphilosophie (1949-1950), pp. 50 ss., donde se compendian las distintas posiciones en torno al tema suscitado.

${ }^{18}$ Gómez de la Serna, José, Filósofos modernos, cit. (n. 8), pp. 105 ss.; ReCaséns, Luis, Panorama del pensamiento jurídico en el siglo XX (México D. F., Porrúa, 1963), I, pp. 51 ss. 
El punto central de la obra stammleriana es el querer, dividido en la especificación del concepto del derecho, junto a las características que le son propias y la aclaración de la legitimidad de ese querer, remitiéndonos al terreno del derecho justo. El derecho pertenece a la esfera fundada en la conexión del medio con el fin, diverso del mundo de la percepción y dominado por la relación causa-efecto. Se trata de una "justificación de los fines", de una "ley para los fines". Stammler adscribe al querer el predicado de ligante en la consideración de reciprocidad que caracteriza al derecho, a la vez que lo distingue del ligado -aquél es la forma o enlace que aúna los contenidos, y cada uno conforma un querer ligado-. Su regulación científica se materializa por una inserción, el concepto del ligante acarrea la idea de sociedad y ha de exteriorizarse ${ }^{19}$.

No obstante, como la obra de la Escuela de Marburgo sobresale, en general, por su logicismo y por dejar al margen los aspectos valorativos, asegura Stammler que la regla exterior no pretende ser el prius de la conducta ordenada en el tiempo, sino su condición lógica que preside el concepto y la ley de la vida social, siguiéndose, consecuentemente, tres ideas: i) Ese concepto no implica una organización estatal; ii) la función lógica que desempeña la regla exterior no es una función causal; y iii) hay una imposibilidad de fases intermedias entre el estado de aislamiento y la vida social ${ }^{20}$.

Así pues, todo lo tratado evidencia el pensamiento de Kant. Para éste, la relación jurídica agrupa las notas de ser externa, recíproca y formal. El ser formal se define porque "en esta relación recíproca de un arbitrio con otro no interesa la materia, es decir, el fin que uno se propone con el objeto que quiere [...] Sólo debe considerarse la forma en la relación de los dos arbitrios y examinar si la acción de uno de los dos puede concordar con la libertad del otro, según una ley universal"21. Ello demuestra la pluralidad de acepciones del formalismo jurídico y su irreductibilidad. Kant es formalista en la definición del derecho, pero no lo es en la definición de la justicia. La teoría del derecho como forma de Kant difiere de la que en la actualidad está más extendida, en cambio, se atisban aspectos concomitantes en cuanto que la coacción es un elemento del derecho positivo. A tal propósito, se debe entender la afirmación hecha por Bobbio de que

${ }^{19}$ LaClaU, Martín, La noción del querer en la filosofía de Rudolf von Stammler, en Revista de Ciencias Sociales, 20 (1982), p. 207.

${ }^{20}$ STAMmLER, Rudolf von, Economía y derecho, p. 77; EL MISMO, Tratado de filosofía del derecho, pp. 94 ss.

${ }^{21}$ Véase la cita que hace Norberto BовBIO en El problema del positivismo jurídico, cit. (n. 1), p. 19, refiriéndose a Kant. Y, sobre el tema, cfr. Cammarata, Angelo Ermanno, Formalismo e sapere giuridico: Studi (Milano, Giuffrè, 1963). 
esta posición es unilateral, pues si observamos los ordenamientos jurídicos, al lado de las normas que dictan la forma en la que deben llevarse a cabo algunos comportamientos, hay normas que evalúan directamente el mérito y la conducta ${ }^{22}$.

Por otra parte, se debe añadir que los elementos de la doctrina de Stammler ofrecen una división entre lo individual y lo social, naciendo y actuando el derecho en el segundo ámbito. Con esta finalidad, se testifica que el hecho histórico del hombre, reflejado en "relaciones recíprocas y mutuo proceder bajo el imperio de ciertas reglas", nunca ha sido deroga$\mathrm{do}^{23}$. El derecho es previo a la sociedad porque es pensable "si existe anteriormente su regla externa", por consiguiente, la experiencia del derecho es lógicamente posterior a su concepto, razón por la que a Stammler no le sirven el procedimiento inductivo ni los conceptos que son objeto de una percepción inmediata. Por sociedad se comprende la vinculación de varios individuos en su posibilidad conceptual, tomando recíprocamente los fines de unos como medios de otros. La expresión "vida social" es convivencia, toda sociedad es una cooperación. La comunidad es una modalidad de la sociedad en la que la voluntad vinculatoria es dirigida por la idea de la voluntad pura ${ }^{24}$.

La postura que Stammler sostiene es que, entre la vida social y la del Estado, la alianza es el hecho de la convivencia, o unidad suprema en la que aspiramos a cifrar el concepto de la vida social, no reducida a la coexistencia de una suma de individuos en un territorio.

Mas no todo acaba aquí, ya que el análisis del concepto de derecho nos lleva obviamente a la reflexión sobre su idea y el ideal social, notificando el paso del concepto a la idea del derecho el salto del conocimiento a la Ética. Stammler juzga que las ideas se muestran ya formadas en la conciencia, tiene que haber, dice, formas puras del pensamiento que "no conserven en su peculiaridad nada de las particularidades de una materia mudable y cambiante, que no sean más que las formas del ordenar unitario". Estas formas son definidas como "líneas rectoras condicionantes". Si recordamos que el concepto del derecho consistía en ser una modalidad del querer, un querer "entrelazante, autárquico e inviolable"; la idea es una remembranza del pensamiento kantiano, puesto que esquematiza la condición de coordinación de las libertades individuales en la sociedad, y es descrita como una especie universalmente válida del pensar jurídico. Es, metafóricamente, "la estrella polar que nos guía a través de los hechos

\footnotetext{
${ }^{22}$ Bobbio, Norberto, El problema del positivismo jurídico, cit. (n. 1), p. 20.

${ }^{23}$ STAMmLER, Rudolf von, Economía y derecho, pp. 80 ss.

${ }^{24}$ STAMmLER, Rudolf von, Tratado de filosofía del derecho, pp. 270 y 271; EL MISMo, Economia y derecho, pp. 96 y 97.
} 
de la experiencia, sin que nunca se presente en toda su integridad en la realidad sensible" 25 .

Esta idea asumida por Stammler adopta una dirección hacia la justicia sentida por una comunidad. Similarmente, la ley última que rige la vida social se traslada a una concepción sobre la comunicación entre el individuo y la comunidad. Toda regulación o aspiración social tiende a un régimen de cooperación y a una conducta de los hombres en sus conexiones recíprocas, sin embargo, según el autor, este fin supremo no se ha de buscar en ningún resultado empírico. A causa de la creencia de que hay una idea del derecho, se justifica un cierto derecho particular. No es un sistema de contenido concreto e invariable, es, más bien, el punto de vista unitario y el enjuiciamiento que lo entronca con los demás derechos pensables ${ }^{26}$.

Su regularidad científica se inserta en el ideal social. Por eso, la voluntad vinculatoria será justa cuando sus normas sean guiadas hacia la comunidad pura, que es "una vinculación de los fines de diversos hombres en que no se retornen por noción determinante y suprema las simples aspiraciones subjetivas de uno de los vinculados". De ahí que la comunidad conforme una pauta que sirva para juzgar la rectitud fundamental de una aspiración, y que la justicia sea la orientación de una voluntad jurídica en la línea de la comunidad pura ${ }^{27}$. A tales efectos, Stammler se pregunta ¿̨bajo qué condiciones ha de reconocerse objetivamente fundado el contenido de una institución, de modo científicamente demostrable?, y ¿cómo podrá aportarse legitimidad objetiva a una aspiración social?, virtualizándose la respuesta en la cualidad formal imputable a una parte del querer y de las normas sociales.

Sobre el tema Stammler piensa que el primer requisito para progresar gravita en un Estado de derecho. Los conceptos de norma jurídica y de sociedad política independiente están condicionados por el de soberano ${ }^{28}$. De esta argumentación dimana la disimilitud entre la forma de plasmar el verdadero progreso del hombre, alcanzando la Verdad y la Justicia, y la materialización de la sociedad, la cual lo realiza "en el caso de que la

${ }^{25}$ En esta línea, Stammler critica a Kant por haber confundido los aspectos del concepto y de la idea del derecho. Véase STAmmLer, Rudolf von, Tratado de filosofía del derecho, p. 4. Cfr. también Fassò, Guido, Historia, cit. (n. 6), III, pp. 158 y 159; Quintana, Fernando, El tema, cit. (n. 13), p. 202.

${ }^{26}$ STAMMLER, Rudolf von, Economía y derecho según la concepción materialista de la Historia. Una investigación filosófico-social, p. 101; El MISMO, Tratado de filosofía del derecho, p. 209.

${ }^{27}$ STAMmLER, Rudolf von, Tratado de filosofía del derecho, pp. 246 ss.

${ }^{28}$ Austin, John, The Province of Jurisprudence Determined (1832). Y el estudio realizado por Isabel TuréGANo en Derecho y moral en John Austin (Madrid, Centro de Estudios Políticos y Constitucionales, 2001), pp. 321 ss. 
marcha de la Historia se desenvuelva conscientemente a tenor de la idea de comunidad pura". En tal paso actuaría el ideal social, que da a conocer a los legisladores la dirección abierta con arreglo a una ley última. Su práctica se refiere a los puntos relacionados a continuación: i) Sistemáticamente, es posible emitir un juicio objetivamente fundado en apoyo a la legitimidad intrínseca del querer y de las aspiraciones sociales; ii) la noción del ideal social y la voluntad de ajustarse a éste tendrán una trascendencia decisiva; y iii) dicha noción podrá adquirirse sin dificultad por la doctrina y las ejemplaridades de otros ${ }^{29}$. En conclusión, la idea no es formal desde un punto de vista categorial y absoluto respecto de lo que aparece como fin último. Lo que en la unificación de los fines humanos hay de puramente formal, y estructura el método de relacionar los términos, es la categoría de identidad o de semejanza subsumiendo el ejemplo en el tipo perfecto, aunque sea para acabar diciendo que el fin último del querer no es realizable y es un proceso formal ${ }^{30}$.

\section{Derecho justo y derecho natural.}

Por lo que respecta al derecho justo y al natural, Stammler quiere mostrar la posibilidad de un derecho justo, y que "el hombre como ser natural no sabe nada de un querer recto; nada tampoco, por lo tanto, de derecho ni de justicia. La idea de la rectitud en el querer y el elegir tiene que ser adquirida”, no importa que la idea de justicia esté más allá de todo derecho justo y se justifique en una idea regulativa. El sistema de derecho justo se remite a la propuesta de las normas y sus destinatarios son "a los que se instituyen las reglas externas". Esta noción es concebida dentro de una forma lógica de ordenación en paralelismo con el intelecto intuitivo de Kant, y en el mencionado punto los conceptos de "comunidad particular" y de "justo medio para el justo fin" son los que, guardando una doble semántica, reincorporan la idea a la realidad ${ }^{31}$.

Conforme a la teoría enunciada, el denominado derecho justo es el positivo que abarca ciertos aspectos, por eso, no hay que ir a un orden

${ }^{29}$ Stammler, Rudolf von, Tratado de filosofía del derecho, p. 448; El Mismo, Economía y derecho, pp. 539 y 540. En este texto, se reconoce una reminiscencia de las concepciones de la justicia platónica y aristotélica por su referente a la igualdad, armonía, equilibrio y proporcionalidad.

${ }^{30}$ Gómez De La Serna, José, Filósofos modernos, cit. (n. 8), pp. 213 ss.

${ }^{31}$ Stammler, Rudolf von, Tratado de filosofía del derecho, pp. 209 ss. Y LaClau, Martín, La noción de justicia en el neokantismo, en Anuario de Filosofia Jurídica y Social (Argentina), 3 (1983); MEDINA, José, Situación presente de la filosofía del derecho (Madrid, Editorial Revista de Derecho Privado, 1935), pp. 57 y 58; Oppen, von, Die Lehre vom richtigen Recht und das deutsche Steuerrecht, en Archiv für Rechts-und Sozialphilosophie (1935-1936), pp. 239 ss. 
normativo externo del humano, sino que se refiere a él, con la advertencia de que los derechos positivos no son justos por el hecho de cumplir el requisito de vigencia en un momento y en un espacio. De forma que, para fijar si poseen justicia, hemos de examinar si están internamente fundados, de ahí que la respuesta sea negativa si el derecho es injusto, o positiva si es justo, cabiendo dos contestaciones más: que sea parcialmente injusto o parcialmente justo. Pero ningún derecho establecido es absolutamente justo, ya que siempre contrae un grado de injusticia e imperfección. Una de las explicaciones más interesantes que aporta Stammler a este grado relativo es la que se expresa por los cambios de las normas que requieren las nuevas circunstancias, labor de adaptación que está en manos de la legislación y la jurisprudencia ${ }^{32}$.

Ahondando en el tema investigado, el derecho positivo es histórico. Acabamos de decir que todo derecho tiene un margen de imperfección, porque ha sido creado por el hombre y el hombre no es perfecto. Cultura es "desenvolvimiento en el rumbo de lo justo", y es la cultura de la sociedad lo cuestionable, moviéndose en un círculo vicioso al conceptuar el derecho justo como aquel que hace posible y fomenta una justa cooperación ${ }^{33}$. Se suscribe que el principio regulativo que nos da pie para llegar a un juicio seguro de la legitimidad objetiva de una regulación, o de una aspiración social, es la idea de una comunidad de hombres de voluntad pura. "La comunidad de hombres de voluntad pura sólo es una idea en el sentido que queda afirmada. No sabemos de ninguna manifestación pero ilumina toda experiencia condicionada”. O sea, que una norma de conducta es justa cuando su particular posición y pretensión concuerda con el ideal de la comunidad de hombres libres. ¿Cuál es éste?, nuestro autor habla del "derecho natural de contenido variable" ${ }^{34}$. Derivativamente, la tesis stammleriana es formalmente separadora del derecho y la justicia. El primero se define siguiendo un método puramente formal de ordenación de los datos de la experiencia jurídica, que a posteriori son confrontados con la idea de justicia.

Desde la perspectiva por la que se aboga, es indispensable hacer hincapié en que esta tesis tiene puntos de contacto que se remontan a autores como Aristóteles y Santo Tomás de Aquino, según las cuales la naturaleza de una cosa es la que sería si actualizara sus posibilidades potenciales (su fin), en el que recae la perfección. Puntualmente, Santo Tomás propugnaba que el hombre cuenta con inclinaciones naturales hacia la propia con-

\footnotetext{
${ }^{32}$ LaRENZ, Karl, Derecho justo: Fundamentos de ética jurídica (traducción al castellano de L. Díez-Picazo, Madrid, Civitas, 2001), pp. 21 ss.

${ }^{33}$ Larenz, Karl, Metodología, cit. (n. 14), p. 110.

${ }^{34}$ STAMmLer, Rudolf von, Economía y derech, pp. 539 y 540.
} 
servación, la propagación de su especie, la persecución de la verdad y la vida en sociedad, prescripciones de las que son derivables máximas menos generales de valor universal. Como corrobora Larenz cuando interpreta esta postura, "para justificar la pretensión de validez tiene que bastar que todo el ordenamiento esté en el camino de lo justo" 35 .

En relación con otras corrientes mucho más tardías, la Escuela del derecho libre, la Jurisprudencia de intereses y el realismo norteamericano someten a revisión la concepción de la realidad jurídica, descubriendo que es fluida y no determinable definitivamente sin que se desvirtúe. La dimensión judicial del derecho exhibe la realidad en forma de juicio de valor sobre un hecho y resalta su necesidad, subordinada a unos esquemas normativos que nos confieren un mínimo de seguridad, de capacidad de previsión de la conducta de los que conviven con nosotros y de control de los llamados a arbitrarla. La Escuela libre se diferencia de la posición de Stammler en que propone un modelo de decisión judicial, la búsqueda de la justicia del caso concreto pospone los ideales de la legalidad y de la seguridad jurídica formal. En cuanto que todo derecho necesita de lo empírico, él es positivo y su aspiración es la de ser derecho recto ${ }^{36}$.

De otro lado, un enfoque clásico del problema axiológico-jurídico se ha concentrado en las doctrinas iusnaturalistas, referidas a las estructuras ontológicas del ser humano y de la vida social. Como confiesa Radbruch, el golpe definitivo contra el derecho natural se dio por la teoría del conocimiento y la filosofía crítica ${ }^{37}$, resurgiendo, posteriormente, con la fórmula del "derecho natural de contenido variable", conceptualizadora de que el criterio de justicia valorativo del derecho positivo proviene del natural, informador de lo que es "formalmente histórico en cada momento"38. Stammler está de acuerdo con el positivismo jurídico historicista y el materialismo histórico, en lo que se remite a que el derecho natural no es inmutable en su contenido ni tampoco se extrae de la naturaleza racional, dado que hay opiniones heterogéneas dirigidas a encontrar lo que

${ }^{35}$ Aquino, Tomás de, Summa Theologica, I-II, q. 94 a. 2 ad 3. Y Véase la interpretación de Miguel SANCHO IZQUIERDO en El derecho justo de Stammler y la ley justa de Santo Tomás. Los conceptos fundamentales de lo justo y lo social en la doctrina tomista, en Universidad (1926), pp. 99 ss. Cfr. también Larenz, Karl, Derecho justo, cit. (n. 32) p. 29; LeGAz, Luis, filosofía del derecho, cit. (n. 8), p. 342.

${ }^{36}$ LarenZ, Karl, Metodología, cit. (n. 14), pp. 82 y 110 . Y Kantorowicz, Hermann U., Zur Lehre vom Richtigen Recht (Berlín, W. Rothschild, 1909).

${ }^{37}$ RadBruch, Gustav, Introducción a la filosofía del derecho (traducción al castellano de W. Roces, Colombia, Fondo de Cultura Económica, 1997), pp. 109 ss.

${ }^{38}$ García Máynez, Eduardo, Filosofía del derecho (México D. F., Porrúa, 2002), p. 502; Pérez Luño, Antonio Enrique, con la colaboración de C. Alarcón Cabrera - R. González-Tablas - A. Ruiz de la Cuesta, Teoría del derecho, cit. (n. 16), p. 76. 
racionalmente responde a la naturaleza del hombre. En lo que difiere es en que hay un aspecto que el positivismo historicista no tiene en cuenta: el de la teoría del conocimiento ${ }^{39}$. Lo que intenta el filósofo es instituir un método formal que tenga una validez general, y que sirva para operar con la materia cambiante regulada por las legislaciones positivas. El problema que se quiere vencer sobre el derecho natural es el de la validez del método y de la materia. Lo válido permanente es la forma a priori, inalterable frente a la mutación de los contenidos.

El derecho natural queda reducido a la idea formalmente explicitada del derecho que se llena de contenidos variables, con tal de que una situación satisfaga los criterios formales. Primeramente, aparece el derecho como categoría de finalidad y, en segundo lugar, como concepto específico; aunque lo cierto es que para Stammler no hay más que una idea del querer, los ideales históricos son diversas cuestiones sometidas al patrón general, o diversas aplicaciones de éste. Doctrina que guarda algunas concomitancias con Suárez, quien articuló armónicamente las exigencias racionales universalmente válidas con las necesidades de cada situación social ${ }^{40}$.

\section{Derecho y moral.}

Pero, con el fin de concretar la teoría suscrita, Stammler precisa más la esfera del derecho percatándose de que la conducta humana no es objeto exclusivo de la regulación jurídica, sino que hay otros sistemas normativos. Sobre esta afluencia, se descompone la frontera con la religión portadora de unos fines: los de la salvación del hombre en una vida futura, más allá de la terrena y material. Otra distinción que acota bien el derecho es la que se proyecta sobre la moral.

La materia de la vida social no es simplemente una trama de impulsos y afanes elementales, habiéndose de diferenciar entre el campo de las intenciones y la voluntad, rectora de la convivencia. Stammler posiciona la condicionalidad de la vida interior en la unidad del hombre aislado, y determina la existencia social por la vinculación de los fines humanos. La cuadratura es la del mundo de los pensamientos, recayendo la variante vida interior-existencia social sobre el criterio formal que diversifica cada aspiración ${ }^{41}$. Críticamente, si nos ceñimos a la distinción kantiana entre

${ }^{39}$ Rodríguez Molinero, Marcelino, Derecho natural e Historia en el pensamiento europeo contemporáneo (Madrid, Editorial Revista de Derecho Privado, 1973), pp. 314 y 315.

${ }^{40}$ STAMmLER, Rudolf von, Economía y derecho, pp. 151 ss. Véase, además, GÓmEZ De La Serna, José, Filósofos modernos, cit. (n. 8), pp. 194 y 282.

${ }^{41}$ Stammler, Rudolf von, Economía y derecho, p. 155; El mismo, Tratado de filosofia del derecho, pp. 91 y 92. 
moral y derecho, cabe ponderar que no es aceptable la bifurcación absoluta de las acciones en internas y externas, puesto que todas tienen un momento interno o psíquico y otro externo o físico. Desde estos postulados, apostilla Stammler que el problema axiológico se apoya en extraer el criterio de la rectitud formal del derecho. En relación con la moral -asegura- los dos conceptos son "contrapuestos, aunque tienen en común ser manifestaciones de la voluntad humana”, lo jurídico se refiere a la acción y lo moral al contenido de la voluntad.

Para el derecho lo que importa es que la conducta justa se realice, valorada por la coacción externa, y para la moral lo relevante es que sea querida, proponiendo a la voluntad una doctrina de la virtud proyectada sistemáticamente ${ }^{42}$. La doctrina contrae la creencia de que el derecho es la regulación de la moral y la moral es la volición del derecho, no habiendo argumento para derivar una de la otra por no concurrir ninguna primacía lógica. Las dos se desprenden "de la ley suprema y única de la voluntad y surgen al aplicar ésta a los conceptos indicados de la moral y de lo social" 43 . Coordinadamente, Stammler piensa que la aplicación de la ley última de la voluntad a la vida interior de cada hombre desemboca en el punto de mira ideal de la pureza interior, es "una noción que expresa la armonía perfecta en el mundo de los deseos". Ahora bien, no hay que olvidar una moral de fines, previa a la regulación jurídica, que ha de ser ofrecida por los legisladores.

Con el objeto de conocer lo que es el derecho, Stammler introduce una noción que pertenece a la moral: el "libre querer", la "pureza de la voluntad”. Asigna a la ley jurídica el propósito de fijar la voluntad, y lo que distancia las dos magnitudes es la misión perseguida, según que tiendan a la vida interna de un individuo o a la existencia en común de los sujetos socialmente vinculados ${ }^{44}$. Con congruencia, suscribe Stammler que las misiones especiales de la ley de unidad que rige el querer son dos. Una explica que el hombre debe tender a que sus deseos sean acordes a una ley última. La segunda incumbe al querer social, aspirante a adaptar la convivencia humana debidamente con sujeción a una ley última. No obstante, ¿dónde ha de encontrarse el criterio decisivo de distinción? El

${ }^{42}$ STAmmler, Rudolf von, Tratado de filosofía del derecho, pp. 67 ss. Y LEGAZ, Luis, Filosofía del derecho, cit. (n. 8), p. 423; Rodríguez Molinero, Marcelino, Introducción a la ciencia del derecho (Salamanca, Librería Cervantes, 1999), p. 85.

${ }^{43}$ STAmmLer, Rudolf von, Tratado de filosofía del derecho, p. 228.

${ }^{44}$ StammLer, Rudolf von, Economía y derecho social, p. 361. Véase también GoNZÁlez ViCÉn, Felipe, El neokantismo jurídico axiológico, en Anuario de Filosofía del Derecho, 3 (nueva época) (1986), pp. 249 ss. 
criterio decisivo -se dictamina- ha de buscarse en el contenido del querer, según que se remita al campo de los deseos o al régimen de cooperación ${ }^{45}$.

\section{CONCLUSIÓN Y VALORACIÓN FINAL}

En definitiva, esta construcción doctrinal nos lleva a concluir que Stammler llamó la atención sobre la urgencia de fabricar una teoría del conocimiento jurídico. Fortaleció la separación entre las ciencias de la naturaleza y las de los fines, a lo que contribuyó la independencia metódica de la jurídica, y superó el positivismo al dotar a la ciencia de la pauta del derecho recto. Entre los puntos más representativos de la doctrina, sobresalen la mentalidad inspirada en creencias dogmáticas racionalistas, el deseo de hallar la pureza del método y el otorgarle una importancia máxima, reduciéndose la idea de la rectitud y sus diversas aplicaciones (moralidad y justicia) a un método formal ${ }^{46}$.

Acuñando lo anterior, según hemos podido advertir, se parte de que el derecho es una forma de ordenar la convivencia, comprendiendo que es un proceso formal armonizador de los fines individuales y sociales, ajustados los primeros a los objetivos comunitarios de un ideal social de justicia cristalizado en una "comunidad de hombres de voluntad libre".

Observado el paralelismo entre "lo referente a las condiciones de posibilidad y validez del derecho positivo y del conocimiento humano", los dos elementos son unidades lógicas. El derecho como ciencia de fines no configura una metafísica en el sentido de $\mathrm{Kant}^{47}$, sino que ambiciona descubrir las líneas generales de una teoría social con alcance absoluto, a la par que fundamentar su filosofía. "El problema social -dice Stammler- no

${ }^{45}$ Stammler, Rudolf von, Economía y derecho según la concepción materialista de la Historia. Una investigación filosófico-social, pp. 355 y 356; EL MISMO, Tratado de filosofía del derecho, pp. 18 ss.

${ }^{46}$ Cfr., en general, Ollig, Hans-Ludwig (editor), Materialien zur Neukantianismus-Diskussion (Darmstadt, 1987); SANDER, Fritz - KelSEN, Hans (edición de S. L. Paulson), Die Rolle des Neukantianismus in der Reinen Rechtslehre (Aalen, Scientia, 1988); Wegner, Arthur, Stammlers Rechtsphilosophie und die Überlieferung der christlichen Völkergemeinschaft, en Archiv für Rechts-und Sozialphilosophie (1935-1936), pp. 320 ss.

47 Aftalión, Enrique R. - Vilanova, José, con la colaboración de J. Raffo, Introducción al derecho, cit. (n. 12), pp. 810 y 811; LARENZ, Karl, Metodología, cit. (n. 14), p. 139. Y García Máynez, Eduardo, Introducción al estudio del derecho (México D. F., Porrúa, 2000), pp. 29 y 30; Goyard-Fabre, Simone, Kant et le problème du Droit (París, J. Vrin, 1975), p. 23, citado por Colomer Martín-Calero, José Luis, La teoria de la justicia de Immanuel Kant, cit., p. 152; Quintana, Fernando, El tema, cit. (n. 13), p. 197. 
podrá ser resuelto nunca. Pues esto equivaldría a que el ideal fuese susceptible de realización [...] No es un estado ideal e incondicionado a lo que aspiran nuestros esfuerzos, sino a una vida social que sea objetivamente justa, a un régimen que, bajo las circunstancias que lo condicionen, posea la cualidad de ajustarse a una ley última. Y esta posibilidad existe"48.

La objeción que autores como Fassò entresacan es que las formas de conocimiento propuestas, aplicables al mundo del derecho, no reflejan los rasgos de las kantianas y, en el supuesto de que no fueran innatas, deberían presuponer el conocimiento empírico del fenómeno del cual intentan configurar la condición trascendental de cognoscibilidad ${ }^{49}$. Stammler encomia un iusnaturalismo que supone una base objetiva y una estructura permanente de contenido histórico ${ }^{50}$, sin contar con que la subordinación del concepto del derecho a su idea aparenta convertirse en una confusión de los dos términos. Sus peculiaridades no delimitan bien la autarquía y la inviolabilidad, y se cubre con estas denominaciones el concepto de obligatoriedad. Por otro lado, la idea es concebida tan ampliamente que queda sin resolver, habiendo autores que la critican puesto que todas proceden de la experiencia ${ }^{51}$.

Con una concepción iusnaturalista, para Corts Grau, la doctrina de Stammler era una ilusión porque, igual que todo concepto, el derecho encerraba un contenido. Lissarrague llegó a decir que la construcción stammleriana era inútil, y que de ella no se podía esperar nada no importándole el verdadero derecho. Y otros, Legaz Lacambra por ejemplo, opinaron que el derecho natural se extinguía en la fórmula aportada de "contenido variable" 52 . Por último, tres son las cuestiones que polemiza

${ }^{48}$ STAMmLer, Rudolf von, Economía y derecho, pp. 18 y 604; El Mismo, Tratado de filosofia del derecho, pp. 3 ss.

${ }^{49}$ Bodenheimer, Edgar, Teoría del derecho (traducción al castellano de V. Herrero, México, Fondo de Cultura Económica, 1986), p. 203; Fassò, Guido, Historia, cit. (n. 6), III, p. 189; STAMMLER, Rudolf von, Economía y derecho, pp. 160 ss.

${ }^{50}$ STAMMLER, Rudolf von, Economía y derecho, pp. 160 ss.

${ }^{51}$ Cfr., entre otras, las críticas de CATHREIn, Victor, Filosofía del derecho, cit. (n. 14), pp. 145 ss.; GonZÁLEZ VICÉN, Fernando, Sobre el neokantismo lógico-jurídico, en Doxa, 2 (1985), pp. 27 ss.; Roces, Wenceslao, Stammler filósofo del derecho y civilista, en Revista General de Legislación y Jurisprudencia, 147 (1925), pp. 449 ss.

${ }^{52}$ Rivaya, Benjamín, Filosofia del derecho y primer franquismo (1937-1945) (Madrid, Centro de Estudios Políticos y Constitucionales, 1998), pp. 293-296; y las referencias hechas a CORTS, José, Filosofía del derecho, I (Introducción gnoseológica) (Madrid, Editora Nacional, 1948); LissarRague, Salvador, El poder político y la sociedad (Madrid, Instituto de Estudios Políticos, 1944); SANCHO IzQUIERDO, Miguel, Tratado elemental de filosofia del derecho y principios de derecho natural (Zaragoza, Librería General, 1943). 
Rodríguez Paniagua: ¿Por qué la constitución de una comunidad de hombres, que quieren libremente la observancia de una armonía plena, es el principio de justificación, la medida para juzgar la justicia?, cuando esa aspiración es generalmente compartida como ideal político. ¿Cómo es posible orientar y dirigir el enjuiciamiento que merecen los contenidos del derecho con fórmulas o principios tan formales y abstractos? $\mathrm{Y}$ ¿no constriñe la justicia, junto a la igualación y equivalencia, a tener también en cuenta la diferenciación y la desproporción entre los diversos sujetos? ${ }^{253}$

\section{BibLIOGRAFíA}

Aftalión, Enrique - Vilanova, José, Introducción al derecho (Buenos Aires, AbeledoPerrot, 1994).

Aquino, Tomás de, Summa Theologica.

ATIENZA, Manuel, El sentido del derecho (Barcelona, Ariel, 2003).

BANFI, Antonio, Il problema epistemologico nella filosofia del diritto e le teorie neokantiane, en Rivista Internazionale di Filosofia del Diritto, 2 (1926).

BINDER, Julius, Rechtsbegriff und Rechtsidee, Bemerkungen zur Rechtsphilosophie Rudolf Stammlers (Aalen, Scientia, 1967).

BobBIo, Norberto, Il problema del positivismo giuridico (Buenos Aires, Editorial Académica de Buenos Aires, 1965).

Bodenheimer, Edgar, Teoría del derecho (traducción al castellano, México D. F., Fondo de Cultura Económica, 1986).

Bulygin, Eugenio, Sobre la regla de reconocimiento, en Carlos AlChOURRÓn - Eugenio Bulygin, Análisis lógico y derecho (Madrid, Centro de Estudios Constitucionales, 1991).

Cammarata, Angelo Ermanno, Formalismo e sapere giuridico: Studi (traducción al castellano, Madrid, Reus, 2002).

Clavel, Maurice, Critique de Kant (Paris, Flammarion, 1980).

Colomer, José Luis, La teoría de la justicia de Immanuel Kant (Madrid, Centro de Estudios Constitucionales, 1995).

Contreras, Francisco J., Rudolf Stammler, en R. Domingo (director), Juristas Universales (Madrid, Marcial Pons, 2004), III.

ConTs, José, Filosofía del derecho (Madrid, Editora Nacional, 1948), I.

FAsso, Guido, Storia della filosofía del diritto (Roma-Bari, Laterza, 2001- 2006), II-III.

FrançoIs, Lucien, Le problème de la définition du droit: Introduction à un Cours d'évolution de la philosophie du droit à lépoque contemporaine (Lieja, Facultad de Derecho, Economía y Ciencias Sociales de Lieja, 1978).

García Máynez, Eduardo, Introducción al estudio del derecho (Méjico D. F., Porrúa, 2000).

${ }^{53}$ Rodríguez Paniagua, José María, Historia del pensamiento jurídico, cit. (n. 10), II, p. 489. Véase también Contreras, Francisco J., Rudolf Stammler, en DoMINGO, Rafael (editor), Juristas universales (Juristas del siglo XIX) (Madrid, Marcial Pons, 2004), III, pp. 678 ss. 
GARRIDO, María Isabel, La teoría y filosofía del derecho de Rudolf von Stammler (Madrid, Reus, 2003).

Ginsberg, Morris, La philosophie du droit de Rudolf Stammler, en Archives de Philosophie du Droit (1932).

Gómez de la SERna, José, Filósofos modernos del derecho. Los neokantianos, en Anuario de filosofía del derecho, 1 (1953).

GonZÁlez VicÉn, Felipe, El neokantismo jurídico axiológico, en Anuario de Filosofía del Derecho, 3 (1986).

GonZález Vicén, Felipe, Sobre el neokantismo lógico-jurídico, en Doxa, 2 (1985).

GONZÁLEZ VICÉN, Felipe, Sobre los orígenes y supuestos del formalismo en el pensamiento jurídico contemporáneo, en Anuario de Filosofia del Derecho, 8 (1961).

Goyard-Fabre, Simone, Kant et le problème du Droit (Paris, J. Vrin, 1975).

HöFfe, Otfried, Immanuel Kant (traducción al castellano, Barcelona, Herder, 1986).

KANT, Immanuel, Crítica de la razón pura (traducción al castellano, Madrid, Tecnos, 2004).

KanT, Immanuel, Fundamentación para una metafisica de las costumbres (traducción al castellano, Madrid, Alianza, 2002).

KANT, Immanuel, Ideas para una historia universal en clave cosmopolita y otros escritos sobre filosofía de la historia (traducción al castellano, Madrid, Tecnos, 2006).

KANT, Immanuel, La metafísica de las costumbres (traducción al castellano, Madrid, Tecnos, 1994).

KANT, Immanuel, Sobre la paz perpetua (traducción al castellano, Madrid, Alianza, 2002).

Kantorowicz, Hermann U., Zur Lehre vom Richtigen Recht (Berlin, W. Rothschild, 1909).

Kaufmann, Erich, Critica della filosofia neokantiana del diritto (Napoli, Edizioni Scientifiche Italiane, 1992).

KÜRY, E. E., Kritische Bemerkungen zu Stammlers Lehre, en Revue Internationale de Théorie du Droit et de Sociologie Juridique, 6 (1931-1932).

LACASTA, José Ignacio, Memoria colectiva, pluralismo y participación democrática (Valencia, Tirant humanidades, 2013).

LaClau, Martín, La noción del "querer" en la filosofía de Rudolf Stammler, en Revista de Ciencias Sociales, 20 (1982).

LACLAU, Martín, La noción de justicia en el neokantismo, en Anuario de Filosofía Jurídica y Social (Argentina), 3 (1983).

LaCroix, Jean, Kant et le kantismo (Paris, Presses Universitaires de France, 1998).

LaREnZ, Karl, Derecho justo: Fundamentos de ética jurídica (traducción al castellano, Madrid, Civitas, 2001).

LARENZ, Karl, Metodología de la ciencia del derecho (traducción al castellano, Barcelona, Ariel, 2001).

LEgAZ, Luis, Filosofia del derecho (Barcelona, Bosch, 1979).

LissarRague, Salvador, El poder político y la sociedad (Madrid, Instituto de Estudios Políticos, 1944).

Llano, Fernando, El formalismo jurídico y la teoría experiencial del derecho (Valencia, Tirant lo Blanch, 2009).

LloyD, Lord Denis, La idea del derecho ¿perversidad represora o necesidad social? (traducción al castellano, Madrid, Civitas, 1985). 
Medina, José, Situación presente de la filosofía del derecho (Madrid, Editorial Revista de Derecho Privado, 1935).

NúNEz EnCABo, Manuel, El derecho, ciencia y realidad social (Madrid, Universitas, 1993).

Ollig, Hans-Ludwig (editor), Materialien zur Neukantianismus-Diskussion (Darmstadt, 1987).

OpPEn, von, Die Lehre vom richtigen Recht und das deutsche Steuerrecht, en Archiv für Rechts-und Sozialphilosophie (1935-1936).

Pascher, Manfred, Einführung in den Neukantianismus (München, Fink, 1997).

Pérez LuÑo, Antonio Enrique, Teoría del derecho. Una concepción de la experiencia jurídica (Madrid, Tecnos, 2008).

QuintanA, Fernando, El tema del concepto y de la idea en Kant y en Stammler, en Revista de Ciencias Sociales, 20 (1982).

RADBRUCH, Gustav, Introducción a la filosofía del derecho (traducción al castellano, Colombia, Fondo de Cultura Económica, 1997).

Recaséns, Luis, Filosofía del derecho (México D. F., Porrúa, 1997).

ReCASÉns, Luis, Panorama del pensamiento jurídico en el siglo XX, vol. I (México D. F., Porrúa, 1963).

RivaYA, Benjamín, Filosofía del derecho y primer franquismo (1937-1945) (Madrid, Centro de Estudios Políticos y Constitucionales, 1998).

Roces, Wenceslao, Stammler filósofo del derecho y civilista, en Revista General de Legislación y Jurisprudencia, 147 (1925).

Rodríguez Molinero, Marcelino, derecho natural e Historia en el pensamiento europeo contemporáneo (Madrid, Edit. Revista de derecho Privado, 1973).

Rodríguez Molinero, Marcelino, Introducción a la ciencia del derecho (Salamanca, Librería Cervantes, 1999).

Rodríguez Paniagua, José María, Historia del pensamiento jurídico (Siglos XIX y $X X)$ (Madrid, Facultad de Derecho de la Universidad Complutense de Madrid, 1997), II.

Sánchez Bustamante, Antonio, Stammler (ensayo de valoración) (La Habana, 1931).

SANCho IzQuierdo, Miguel, El derecho justo de Stammler y la ley justa de Santo Tomás. Los conceptos fundamentales de lo justo y lo social en la doctrina tomista, en Universidad (1926).

SAnCho IzQuierdo, Miguel, Tratado elemental de filosofía del derecho y principios de derecho natural (Zaragoza, Libr. General, 1943).

SANDER, Fritz - Kelsen, Hans, Die Rolle des Neukantianismus in der Reinen Rechtslehre (ed. de S. L. Paulson, Aalen, Scientia, 1988).

Solari, Gioele, L'indirizzo neo-kantiano nella filosofia del diritto, en Rivista di Filosofia, 23 (1932).

Truyol, Antonio, Historia de la filosofia del derecho y del Estado (Madrid, Alianza, 2007), II.

Turégano, Isabel, Derecho y moral en John Austin (Madrid, Centro de Estudios Constitucionales, 2001).

WaRAT, Luis, Los presupuestos kantianos y neokantianos de la teoría pura del derecho, en Revista de Ciencias Sociales, 20 (1982).

Wegner, Arthur, Stammlers Rechtsphilosophie und die Überlieferung der christlichen Völkergemeinschaft, en Archiv für Rechts-und Sozialphilosophie (1935-1936). 
Williams, Glanville L, The Controversy Concerning the Word "Law", en Archiv für Recht-und Sozialphilosophie (1949-1950).

Wu, John C.H., Stammler and his Critics, in Modern Legal Philosophy Series, 8 (New York, 1969). 

